\title{
O TÍTULO E SEU PAPEL DE DESTAQUE NO TEXTO
}

Catarina Borges de Oliveira Ribeiro (UERJ)

Tania Maria Nunes de Lima Câmara (UERJ)

Resumo: Este artigo demonstra a importância do título no texto, considerando-o não apenas como um complemento deste, mas, sim, como um componente atrativo, capaz de captar a atenção do leitor em um primeiro momento, revelando-se, portanto, um fator estratégico e orientador para a interpretação textual. Outro aspecto que merece destaque é que, além de possuir um lugar privilegiado, ele também guarda a subjetividade do autor. Além disso, ele deve preservar uma macroestrutura semântica elevada que se relacione com o conteúdo do escrito, mostrando-se interessante e coerente. Nesse sentido, este artigo pretende utilizar o espaço escolar para apresentar aos alunos tipos de intitulação, tanto as que guardam relação semântica com o texto, quanto as que não possuem esse entrelaçamento claro, com o intuito de incentivá-los na prática de produção textual, destacando a importância do título e, ao mesmo tempo, fornecendo mecanismos para lhes expandir a criatividade, assunto praticamente não trabalhado pelo professor da Educação Básica.

Palavras-chave: Educação básica; Língua Portuguesa; Produção Textual; Título.

Abstract: This article demonstrates the importance of the title in the text, considering it not only as a complement to it, but as an attractive component, capable of capturing the reader's attention at the first moment, thus revealing itself as a strategic and guiding factor for textual interpretation. Another aspect that deserves to be highlighted is that, besides having a privileged place, it also keeps the author's subjectivity. In addition, it must preserve an increased semantic macrostructure that relates to the content of the writing, proving to be interesting and coherent. In this sense, this article intends to use the school space to present the types of titles, as well as keeping the semantic relationship with the text, as well as not having this clear interlacing, in order to encourage the practice of textual production, highlighting the importance of title and, at the same time, providing mechanisms to expand creativity, a subject practically not dealt by the teacher of Basic Education.

Keywords: Basic education; Portuguese language; Writing; Title. 


\section{INTRODUÇÃO}

O presente trabalho tem $\mathrm{O}$ intuito de demonstrar a importância do título para o texto. Independente do gênero escolhido pelo autor, o nome da obra deve se relacionar ao conteúdo, dando pistas ao leitor a respeito do que ele encontrará em sua leitura. O que está por trás de um bom título e de sua estrutura é o que este artigo pretende elucidar. Para isso, serão analisados textos cujos títulos, ao lado de se relacionarem bem com as ideias expostas, também trazem ou um lado criativo ou uma falha estrutural.

O título dos textos em geral pode ser visto sob dois pontos de vista: anafórico ou catafórico. O ponto de vista catafórico ocorre quando, no primeiro contato com o texto, o nome da obra dá indícios do tema abordado, de forma prévia. Entretanto, do ponto de vista do autor, o qual já teve contato com o conteúdo textual, pelo fato de tê-lo produzido, o título é visto como anafórico, por retomar todas as ideias apresentadas, conforme esclarecem Menegassi e Chaves (2000, p.33).

Godoi (2011, p.2) esclarece que o título da obra acaba sendo retomado no texto por meio de expressões que o identificam, dando indícios de referenciação, os quais contribuem para a formação textual. Desse modo, para 
embasar sua explicação sobre a construção e a ligação entre título e conteúdo, a professora cita o linguista brasileiro Luiz Antônio Marcuschi (MARCUSCHI, 2005, Apud GODOI, 2011, p.2), explicando a teoria da anáfora direta e indireta acerca do nome da obra, considerando, portanto, o título como um "antecedente virtual".

Segundo Teun van Dijk (VAN DIJK, 1992, Apud CORRÊA, 1999, p.66), o texto deve ter um mecanismo de funcionamento e, em função disso, estabelece uma divisão em sua estrutura: a macroestrutura textual, a microestrutura e a superestrutura. A primeira está associada ao conteúdo global do texto, ou seja, à sequência discursiva; a segunda, às pequenas composições que juntas formarão a macroestrutura; e, por sua vez, a superestrutura é o que estabelecerá forma e conteúdo da obra, ou seja, seria o tipo textual: expositivo, argumentativo, narrativo, dentre outros.

A importância de uma boa composição textual, que respeite as estruturas acima mencionadas, influenciará na eficácia do título e nas informações prévias que ele fornece ao leitor, afinal as seleções realizadas em sua estruturação trarão indícios do que será encontrado no texto.

Cabe considerar ainda que o título também pode apresentar uma função intertextual, conectando a obra 
a um texto externo, desde que este esteja conectado ao conteúdo abordado. A essa inter-relação dá-se o nome de função intertextual. Portanto, visando à demonstração de títulos criativos, os quais incentivem os alunos em suas produções textuais, serão apresentados textos cujos títulos e conteúdos apresentam tal correlação, revelando efeitos produtivos, quais sejam:

(i) Pepino maluquinho, o mais levado da hortifruti, propaganda da rede de mercados Hortifruti em 2007;

(ii) Vacina sem revolta - artigo de opinião publicado no jornal Folha de São Paulo, de 27 de agosto de 2018;

(iii) Os profissionais de saúde sérios do mundo inteiro advertem: desrespeitar a ciência faz mal à saúde, capa do jornal Extra de 16 de maio de 2020.

Destaque-se que a proposta da presente pesquisa, a qual tem o intuito de trabalhar prática de leitura e produção de texto em sala de aula, baseia-se nas proposições dos Parâmetros Curriculares Nacionais (PCN, 2000), que priorizam o ensino da Língua Portuguesa atrelado à leitura e escrita, por reconhecer que o ensino da língua deve estar conectada ao contexto social.

Cabe, ainda, mencionar a nova diretriz oficial para o planejamento de ensino: a Base Nacional Comum Curricular 
- BNCC. De acordo com o disposto no texto, trata-se de "um documento de caráter normativo que define o conjunto orgânico e progressivo de aprendizagens essenciais que todos os alunos devem desenvolver ao longo das etapas e modalidades da Educação Básica" (BNCC, 2017, p.5). Sendo assim, a proposta deste trabalho é abordar o estudo do título a partir das competências da Base Nacional Comum Curricular. Entre elas, podem ser citadas: (2) apropriação da linguagem escrita; (7) reconhecimento do texto como lugar de manifestação e negociação de sentidos, valores e ideologias; (8) leitura integral de textos com objetivos e interesses específicos como entretenimento, formação pessoal e estudo).

\section{ESTRUTURA DO TEXTO}

Todo texto possui uma estrutura que the confere características específicas e essas poderão ajudar a determinar o gênero textual do escrito. Conforme explica Marcuschi, "em qualquer contexto discursivo, os gêneros são instrumentos estanques e enrijecedores da ação criativa. Caracterizam-se como eventos textuais altamente maleáveis, dinâmicos e plásticos" (2002, p.19). O autor traz essa informação para iniciar suas explicações acerca das infinitas possibilidades de estrutura de um texto, ainda 
mais na atual cultura tecnológica, quando uma conversa de whatsapp é considerada gênero textual. Dessa forma, alguns dos "novos" gêneros citados pelo autor, os quais, na verdade, não podem ser considerados tão originais (novos) assim, pois sofrem mudanças e/ou adaptações no decorrer do tempo e com a frequência de seu uso, têm origem nos e-mails, batepapos virtuais, nas videoconferências, nos editoriais, artigos de fundo, horóscopos, entre outros.

Sendo assim, cabe esclarecer onde se enquadra a importância de desvendar o gênero para uma boa intitulação e a resposta para esse questionamento é muito simples: é a partir da "roupagem" do texto que se sabe: (i) a quem a obra é destinada (enunciatário), (ii) onde será divulgada (iii) e qual o seu objetivo. Considerando esses três itens, em atenção ao conteúdo e à escolha do tipo textual, é possível criar um título atrativo e/ou provocativo que sintetize, implícita ou explicitamente, a intenção comunicativa do autor.

Para diferenciar tipo textual de gênero textual, Marcushi estabelece quatro características para cada uma das modalidades e as contrapõe:

Tipos Textuais: 1 . constructos teóricos definidos por propriedades lingüísticas intrínsecas; 2 . constituem sequências linguísticas ou sequências de enunciados e não são textos empíricos; 3 . sua nomeação 
abrange um conjunto limitado de categorias teóricas determinadas por aspectos lexicais, sintáticos, relações lógicas, tempo verbal; 4. designações teóricas dos tipos: narração, argumentação, descrição, injunção e exposição. (2002, p.23-24)

Gêneros Textuais: 1. realizações linguísticas concretas definidas por propriedades socio-comunicativas; 2 . constituem textos empiricamente realizados cumprindo funções em situações comunicativas; 3 . sua nomeação abrange um conjunto aberto e praticamente ilimitado de designações concretas determinadas pelo canal, estilo, conteúdo, composição e função; 4. exemplos de gêneros: telefonema, sermão, carta comercial, carta pessoal, romance, bilhete, aula expositiva, reunião de condomínio, horóscopo, receita culinária, bula de remédio, lista de compras, cardápio, instruções de uso, outdoor, inquérito policial, resenha, edital de concurso, piada, conversação espontânea, conferência, carta eletrônica, bate-papo virtual, aulas virtuais etc. (2002, p.23-24)

Estabelecidas as diferenças destacadas pelo autor mencionado, nota-se o quanto esse conhecimento pode auxiliar o aluno na hora de iniciar a sua produção escrita, o que deve ser trabalhado em sala de aula desde o Ensino Fundamental I, com intuito de evitar que o aluno chegue ao Ensino Médio com dificuldade em identificar o gênero de um texto, o que certamente prejudicará seu desempenho na hora de realizar uma composição escrita. Ademais, 
como já se demonstra neste artigo, apenas uma construção adequada de texto, com organização na exposição das ideias, será possível criar um título relacionado à obra e, ao mesmo tempo, criativo, fugindo das redações comuns e sendo, portanto, capaz de captar a atenção do leitor em meio a tantas opções presentes no mundo exterior. Como prática de sala de aula, podem ser realizadas atividades que introduzam o tema e, de forma lúdica, incentivem os alunos a decifrar o gênero e o tipo textual e, logo após essa etapa, escolham um título para a obra.

Para a criação de um bom texto e, consequentemente, de um título que transmita, de maneira adequada, o conteúdo naquele contido, é importante reconhecer os tipos textuais, pois é a partir do tipo textual que se tem a construção sequencial da composição. Os mais utilizados são narração, argumentação, exposição, descrição, injunção.

É importante mencionar que um mesmo texto pode mesclar os tipos textuais acima elencados, no entanto um deles predominará na composição da obra. Um bom exemplo disso é um texto argumentativo, o qual, para convencer ou persuadir o enunciatário em relação a um determinado ponto de vista, aconselha-se o autor a realizar, por exemplo, a descrição de alguns elementos, a narração de alguns fatos, apresentação de dados, por exemplo. 
Saber diferenciar tipo textual de gênero textual contribui significativamente para o bom desenvolvimento do texto, levando o aluno à escolha lexical adequada ao conteúdo e, por fim, ao título.

\section{TíTULO E SUAS FUNÇÕES}

O título é o elemento que ocupa a posição de destaque na obra; apesar disso, raramente os autores refletem acerca dessa construção, não havendo, portanto, um trabalho realizado com frequência que conduza a um procedimento criativo e organizado para sua criação. Essa prática pode ser realizado desde as séries iniciais, considerando que o aluno, ao finalizar a produção textual, não seja levado a escolher qualquer título para nomear o texto, evitando clichês ou até mesmo repetindo o tema da redação, o que reflete descuido ou falta de incentivo à criatividade.

A posição de destaque do título, além de ser visível para o leitor, é sempre destacada por alguns autores, como, por exemplo, Corrêa (1999), que reflete sobre a importância do título como algo que deve "chamar a atenção do leitor para o texto" (CORRÊA, 1999, p.13). E, mais adiante, completa: “o título é como um anúncio publicitário, cujo objetivo é vender seu produto: a notícia (ou outro tipo de texto qualquer publicado no jornal, como o artigo, a reportagem, a coluna, o editorial etc.)" (1999, p.13). Diante dessa informação, nota- 
se que existe, efetivamente, um processo de intitulação, o qual faz parte da prática da escrita.

O que se pretende é chamar atenção daquele que produz um texto para os cuidados que ele deve ter ao nomear a sua obra, uma vez que o título tem algumas funções, conforme será demonstrado abaixo.

Acerca dessas funções, pode-se verificar as seguintes: anafórica, catafórica e intertextual, como anteriormente exposto, esclarecidas por Coracini, citada por Menegassi e Chaves (2000):

Coracini (1989) comenta que o título é o lugar privilegiado da subjetividade do autor; é anafórico do ponto de vista da produção escrita, considerando que é redigido depois do texto; é catafórico no processo de leitura porque anuncia, em parte, o conteúdo presente no texto, constituindo, assim, uma estratégia a serviço das intenções do autor, pois, "ao mesmo tempo em que camufla o percurso do texto, exerce grande influência sobre o leitor, na medida em que funciona como estímulo e desestímulo à leitura." (CORACINI, 1989, Apud MENEGASSI; CHAVES, 2000, p.33)

Ademais, ele pode ser canônico ou enviesado, conforme conceitua Corrêa (1999). Todos esses conceitos devem ser apresentados, de forma adequada, ao estudante, na medida em que também envolvem a produção escrita. 
a) Função anafórica e catafórica do título

Quando se fala em função anafórica, logo vem à ideia algo que já foi apresentado ou dito, e assim também ocorre no processo de intitulação. O título tem função anafórica do ponto de vista do autor, pois ele já possui conhecimento do conteúdo quando nomeia a obra.

Alguns autores, como Godoi (2011), consideram que é possível uma subdivisão nessa classificação, existindo a anáfora direta e a indireta, conforme propõe Marcuschi (2002), o qual é citado pela autora. Nesse sentido, tem-se que anáfora indireta se acha

em dependência interpretativa em relação ao Título [...]. O fato de considerarmos o Título do texto como parte do cotexto é o que nos abre caminho para considerá-lo como antecedente, de certa forma virtual, para os referentes imbricados na superfície do texto. Partindo desse pressuposto, não podemos desconsiderar, no entanto, a possibilidade do surgimento, também, da Anáfora Direta em nossas análises. (GODOI, 2011, p.7)

A autora expõe que, como o título é considerado parte do texto, ele possui, sim, uma função anafórica indireta e, por essa razão, surge, em consequência, o conceito de anáfora direta. Essa última é a que estabelece uma relação de coreferência entre o elemento anafórico e o seu antecedente (MARCUSCHI, 2005, Apud GODOI, 2011, p.8). 
A função catafórica é aquela que se refere a algo que ainda não foi mencionado no texto. Em relação ao título, ela constitui uma função exclusiva do enunciatário, o qual não tem conhecimento prévio do conteúdo da obra, o que confirma a ideia de título como o lugar mais importante do texto (privilegiado) e por isso o elemento mais atrativo.

Nesse contexto, Menegassi e Chaves (2000, p.32) afirmam que "o título é um estímulo inicial que ativa os esquemas do leitor, proporcionando os cálculos cognitivos, quando é pertinente ao texto, ou melhor, quando é uma macroproposição de nível mais alto". Ambos ainda esclarecem que o título tem o poder de orientar a interpretação da obra, o que fortalece, ainda mais, a sua função estratégica.

b) Processo de ancoragem e função intertextual

Alguns dos autores já citados também aludem ao processo de ancoragem do título, sendo essa uma formulação de Marcushi (2005). Trata-se de uma análise feita em alguns textos, os quais apresentam informações novas, que ainda não haviam sido explicadas, mas que surgiam como já conhecidas. Essas expressões mantêm estreita relação ou se ancoram cognitivamente no título (GODOI, 2011, p.6).

Ao abordar o processo de ancoragem, Menegassi (2000) releva alguns traços que remetem à função intertextual do 
título: "às vezes, a ancoragem do texto no título processa-se por uma ligação exofórica, remetendo o leitor a um elemento exterior, não anunciado no texto, mas presente nos seus esquemas". A explicação do autor traça um paralelo com as características de um título que traz informações prévias, as quais já é esperado serem de conhecimento do leitor, como, por exemplo, o título da notícia Vacina sem revolta, que será apresentado adiante. Esse texto, só pelo título, conecta o enunciatário à Revolta da Vacina ocorrida em 1904, no Rio de Janeiro, exigindo por parte do leitor conhecimento de mundo para uma leitura adequada, até mesmo pelo léxico escolhido para compor a macroestrutura textual.

O título pode ser divido em dois modelos, canónicos e enviesados, conforme a sua estrutura e conexão com o texto. Côrrea explica muito bem a diferença entre eles, afirmando que:

os primeiros são aqueles que trazem a informação mais importante do texto, a sua ideia central, funcionando como uma espécie de resumo do resumo desse texto; os últimos são aqueles que promovem uma informação de menor importância à categoria de ideia central do texto. (1999, p.54)

Importante destacar que, independente de o título ser canônico ou enviesado, ele pode ter uma estrutura verbal 
ou nominal. No primeiro caso, apresentará um verbo, o que é muito comum em notícias, já, no segundo caso, ele será sustentado por um "nome", ou seja, adjetivos, advérbios, substantivos. Abaixo veremos alguns exemplos de títulos canônicos.

\section{ANÁLISE DO CÓRPUS}

Os textos escolhidos para sintetizar o presente estudo podem ser apresentados da seguinte forma:

a) título canônico verbal: "Os profissionais de saúde sérios do mundo inteiro advertem: desrespeitar a ciência faz mal à saúde.".

Refere-seà capa dojornal Extra de 16 de maio de 2020, a qual dialoga com uma série de eventos extrínsecos envolvendo a pandemia do Coronavírus. O título, extremamente chamativo, capta a atenção do leitor por reformular a mensagem do Ministério da Saúde "Se persistirem os sintomas, o médico deverá ser consultado", traz conhecimento popular, presente em propagandas de remédios e de cigarros, o que marca a intertextualidade. Nesse sentido, enunciado publicitário aponta para a falta de bom senso dos profissionais que, mesmo durante o surto de COVID-19 pelo mundo, optaram por ignorar as consequências da doença e agem como se o mundo passasse por um simples surto de gripe. 
b) título canônico nominal: "Pepino maluquinho, o mais levado da hortifruti".

Trata-se de uma propaganda da rede de mercados Hortifruti veiculada no final do ano de 2007. O título é nominal e faz alusão à obra $O$ menino maluquinho, do cartunista Ziraldo Alves Pinto. Mais uma vez, é possível perceber a função intertextual como um recurso que une elementos intrínsecos e extrínsecos, pois exige do leitor conhecimento de mundo para decodificar a mensagem.

c) título canônico nominal: "Vacina sem revolta".

Trata-se de uma notícia veiculada no jornal Folha de São Paulo, publicada dia 27 de agosto de 2018. Esse título é um dos que muito bem se encaixa na concepção de canônico, pois, além da função intertextual, já que retoma a Revolta da Vacina ocorrida no Rio de Janeiro em 1904, mas afirma o seu oposto.

Importante ressaltar que, apesar de os títulos nominal e verbal também serem canônicos, tendo em vista a conexão existente entre o conteúdo da obra e a nomenclatura, a escolha da notícia para representar o título canônico se deu em razão do léxico presente na macroestrutura do texto. 


\section{CONSIDERAÇÕES FINAIS}

Diante dos conceitos e informações aqui expostos, nota-se que o título não é apenas um enfeite no texto, independente do gênero textual ao qual pertença. Ao contrário, deve ser encarado como elemento que ocupa papel relevante na obra e, por essa razão, deve respeitar determinados procedimentos para adequar-se perfeitamente ao texto e exercer sua função primordial, qual seja: captar a atenção do leitor, orientar o caminho de leitura a ser feito e demonstrar de forma sintética o conteúdo do texto.

Sendo assim, o intuito desta pesquisa, ainda em fase inicial, é trazer para a academia reflexões sobre o tema, com o intuito de incentivar outros estudos sobre o tema, bem como torná-lo objeto de estudo dos alunos por meio de práticas de leitura e produção escrita, no intuito de fazê-los perceber o quanto é importante o processo de intitulação, não sendo essa uma simples etapa realizada após o término do desenvolvimento textual.

\section{REFERÊNCIAS}

BRASIL (2000). MEC/SEMTEC. Parâmetros curriculares nacionais: Ensino Médio. Brasília, MEC/ Secretaria e Educação Média e Tecnologia.

(2017). Ministério da Educação. Base Nacional Comum Curricular. Brasília: MEC.

CORRÊA, Hécules Toledo (1999) "Títulos e macroestruturas textuais". Rev. Est. Ling, Belo Horizonte, 8(2), Jul./Dez., 53-78. 
GODOI, Eliamar (2011) "O título e os processos de referenciação". Anais do SILEL, 2(2), Uberlândia: EDUFU.

HORTIFRUTI (2007). Pepino Maluquinho. In https://maeperfeita.files. wordpress.com/2013/04/pepino-maluquinho.jpg Acesso em: 5.Jun.2020. MARCUSCHI, Luiz Antonio (2002). "Gêneros textuais: definição e funcionalidade". In: DIONíSIO, Angela Paiva; MACHADO, Anna Rachel; BEZERRA, Maria Auxiliadora (Orgs.). Gêneros textuais \& ensino. 3.ed. Rio de Janeiro: Lucerna, p.19-36.

MENEGASSI, Renilson José; CHAVES, Maria Izabel (2000). "O título e sua função estratégica na articulação do texto". Linguagem \& Ensino, Paraná: Maringá, 3(1), 27-44.

OSPROFISSIONAIS desaúde sérios do mundo inteiroadvertem: desrespeitar a ciência faz mal à saúde (2020). Extra. Rio de Janeiro, 16 de maio. In https://extra.globo.com/capas-jornal-extra/2020-05-60-24430846.html? mesSelecionado=Mai\&ano=2020 Acesso em: 5.Jun.2020.

VACINA sem revolta (2018). Folha de São Paulo. São Paulo, 27 de agosto. In https://www1.folha.uol.com.br/opiniao/2018/08/vacina-sem-revolta. shtml Acesso em: 5.Jun.2020.

Catarina Borges de Oliveira Ribeiro é Bacharel em Direito pela UCAM câmpus Méier. Mestranda em Língua Portuguesa (UERJ). Graduanda em Letras Português-Alemão (UERJ). Bolsista de Iniciação Científica da UERJ. Autora do artigo "Título: Eita Escolha Difícil". Membro do grupo de pesquisa Práticas sociais da expressão linguística e práticas escolares: leitura, produção textual, ensino. Foi bolsista de extensão no projeto LABSEM (UERJ).

Email: catarinauerj@gmail.com.

ORCID iD: https://orcid.org/0000-0002-0991-3370.

Tania Maria Nunes de Lima Camara é Doutora em Letras pela UERJ. Coordenadora do curso Português para a comunidade do programa LICOM /PLIC da UERJ. Atua nos cursos de Doutorado e Mestrado em Língua Portuguesa, e Graduação em Letras da UERJ, câmpus Maracanã. É autora da obra As múltiplas faces do ser machadiano: um olhar crítico sobre os nomes próprios e organizadora das obras Língua Portuguesa: 
tradições e modernidade; Estudos de Língua Portuguesa: reflexões; Língua Portuguesa: descrição e ensino. Coordenadora do grupo de pesquisa Práticas sociais da expressão linguística e práticas escolares: leitura, produção textual, ensino. Área de atuação: ensino de Língua Portuguesa: leitura, gramática e produção textual.

Email: taniamnlc@gmail.com.

ORCID iD: http://orcid.org/0000-0003-0976-9361.

Recebido em 10 de julho de 2020 Aprovado em 13 de agosto de 2020 